\title{
Loss Computation of Multilayer Coplanar Waveguide using Single Layer Reduction Method
}

\author{
A. K. Verma, Paramjeet Singh* \\ Department of Electronic Science University of Delhi South Campus, New Delhi 110021, India
}

\begin{abstract}
In this paper, the quasi-static spectral domain approach (SDA) and single layer reduction (SLR) method applicable for multilayer coplanar waveguide (CPW) on isotropic dielectric substrate that incorporates two layer model of conductor thickness is used to compute the impedance, effective dielectric constant, dielectric loss and conductor loss. The transverse transmission line (TTL) technique is used to find the Green's function for the multilayer CPW in Fourier domain. Dielectric loss of multilayer coplanar waveguide is computed by converting multilayer CPW structure into equivalent single layer CPW using SLR method. Perturbation method is used to compute the conductor loss. The effect of finite conductor thickness is analysed on the impedance, effective dielectric constant, dielectric loss and conductor loss. The present formulation also accounts for low frequency dispersion in computation of quasi-static effective dielectric constant and characteristic impedance.
\end{abstract}

Keywords Conductor Loss, Dielectric Loss, Multilayer Coplanar Waveguide, Quasi-Static Spectral Domain Approach, Single Layer Reduction Method, Transverse Transmission Line Technique

\section{Introduction}

There has been a growing interest in different configurations of coplanar waveguide (CPW) transmission line such as conductor backed CPW, CPW with finite ground width, shielded multilayer CPW, elevated or suspended $\mathrm{CPW}$, asymmetric CPW etc. The CPW offers many advantages over microstrip line such as easy connection of both series and shunt components without drilling holes through the dielectric substrate, less dispersive and provides ease of controlling the characteristics of line by changing the strip and slot width. Therefore, CPW transmission lines are widely used in the design of components and interconnect in modern microwave circuit design. The accurate modelling of transmission lines is important in the design and development of modern integrated circuits. Most research done in literature on CPW was based under the assumption of zero conductor thickness using the conformal mapping and spectral domain approach (SDA) method. But in practical cases, the conductor thickness can not be zero and affects the impedance, effective dielectric constant and losses etc. Several research papers have been presented to characterize planar transmission line structure with finite metallization thickness[1-13].

This paper presents the effects of finite strip thickness on

* Corresponding author:

paramwes@yahoo.co.in (Paramjeet Singh)

Published online at http://journal.sapub.org/ijea

Copyright (C) 2012 Scientific \& Academic Publishing. All Rights Reserved the impedance, effective relative permittivity, dielectric loss and conductor loss of multilayer CPW structures using quasi-static SDA method on isotropic dielectric substrate. Dispersion characteristics of multilayer CPW is also analysed using single layer reduction (SLR) method.

\section{Coplanar Waveguide Analysis}

The conventional CPW consist of centred conductor between two infinite ground planes with all on the same plane. The height of substrate is also infinite. But in practical case, both the width of the ground planes and height of substrate are finite. The cross section structure of shielded mu ltilayer coplanar waveguide of fin ite conductor thickness under investigation using the quasi-static SDA formulation is shown in Figure. 1.

In this paper an efficient method for calculating the line capacitance of shielded multilayer CPW of finite conductor thickness is presented. The effect of conductor thickness is accounted by accommodating the two layer strip conductor model that is suggested for a microstrip line[4]. The potential and charge distribution basis function on the strips is required to compute the line capacitance. The potential on the strips is expressed in terms of charge distribution on the upper and lower strips. The unknown charge distribution function can be expanded in term of linear combination of basis function. The total potential in the range $[0, \mathrm{~L}]$ is equal to the sum of the potential on strips conductor and potential in two slot region. Then, Galerkin method is applied to find the unknown coefficient of chare density basis function. The 
total charge on the coplanar waveguide is sum of charge at upper and lower strip of centre conductor. Therefore, quasi-static SDA obtains the total charge on the central strip. By using the total charge on the central strip the per unit length capacitance is computed. The effective dielectric constant and characteristic impedance of the CPW transmission line can be determined using capacitance per unit length.

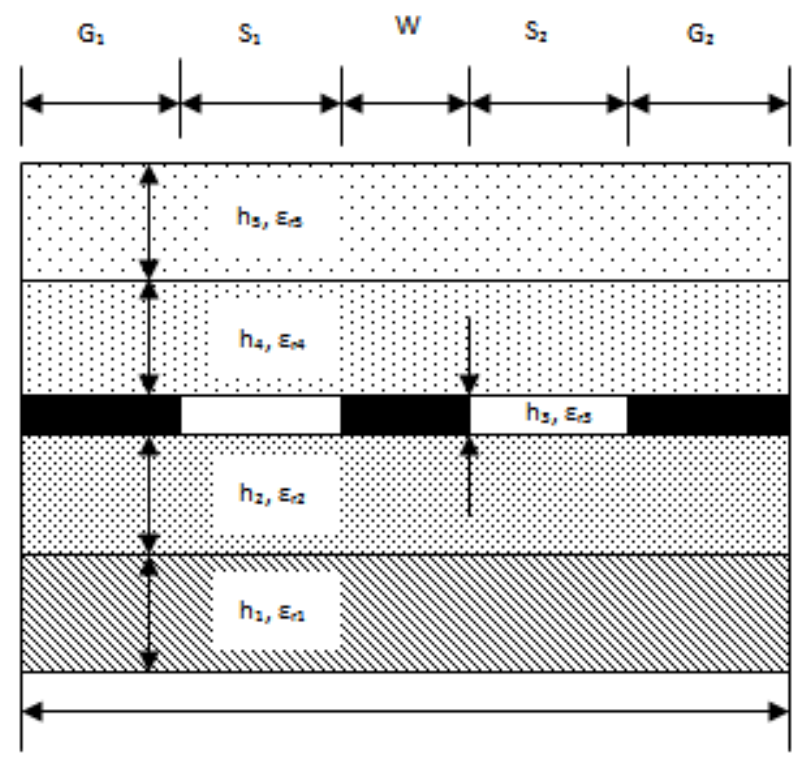

0

Figure 1. Multilayer Shielded Coplanar Waveguide

The charge density basis functions are confined only on conductors strip and are zero outside the conductor strips. The basis function for the charge for centre strip $\mathrm{W}$, left ground $\mathrm{G}_{1}$ and right ground $\mathrm{G}_{2}$ strip is $\rho_{\mathrm{s} 1 \mathrm{i}}(\mathrm{x}), \rho_{\mathrm{s} 2 \mathrm{i}}(\mathrm{x}), \rho_{\mathrm{s} 3 \mathrm{i}}(\mathrm{x})$ respectively, where $i=1,2,3 \ldots$ the number of basis terms of the corresponding strips. The Fourier transform of these basis functions of charge density on central conductor of width $W$, left ground $G_{1}$ and right ground $G_{2}$ are $\widetilde{\rho}_{\mathrm{sli}}\left(\beta_{\mathrm{n}}\right), \widetilde{\rho}_{\mathrm{s} 2 \mathrm{i}}\left(\beta_{\mathrm{n}}\right), \widetilde{\rho}_{\mathrm{s} 3 \mathrm{i}}\left(\beta_{\mathrm{n}}\right)$ respectively. In the spectral domain, the charge density basis function for lower and upper surface of conductor plane is given by$\widetilde{\rho}_{s i}\left(\beta_{n}\right)=$

$$
\left[\begin{array}{l}
\sum_{i=1}^{N_{1}} a_{i}^{1} \widetilde{\rho}_{s 1 i}\left(\beta_{n}\right)+\sum_{i=1}^{N_{1}} b_{i}^{1} \widetilde{\rho}_{s 2 i}\left(\beta_{n}\right)+\sum_{i=1}^{N_{1}} c_{i}^{1} \widetilde{\rho}_{s 3 i}\left(\beta_{n}\right) \\
\sum_{i=1}^{N_{1}} a_{i}^{2} \widetilde{\rho}_{s 1 i}\left(\beta_{n}\right)+\sum_{i=1}^{N_{1}} b_{i}^{2} \widetilde{\rho}_{s 2 i}\left(\beta_{n}\right)+\sum_{i=1}^{N_{1}} c_{i}^{2} \widetilde{\rho}_{s 3 i}\left(\beta_{n}\right)
\end{array}\right]
$$

where, $\mathrm{a}_{\mathrm{i}}^{1}, \mathrm{~b}_{\mathrm{i}}^{1}, \mathrm{c}_{\mathrm{i}}^{1}$ and $\mathrm{a}_{\mathrm{i}}^{2}, \mathrm{~b}_{\mathrm{i}}^{2}, \mathrm{c}_{\mathrm{i}}^{2}$ are unknown constant coefficients associated with central conductor, left ground and right ground respectively for lower and upper surface of the conductor, $\mathrm{N}_{1}$ is number of bas is function. The Green's function and the basis function in Fourier do main are related to potential on strip and slot region by following expression,

$$
\widetilde{\mathrm{G}}\left(\beta_{\mathrm{n}}\right) \widetilde{\rho}_{\mathrm{si}}\left(\beta_{\mathrm{n}}\right)=\widetilde{\mathrm{V}}_{\mathrm{c}}\left(\beta_{\mathrm{n}}\right)+\widetilde{\mathrm{V}}_{\mathrm{d}}\left(\beta_{\mathrm{n}}\right)
$$

where $\widetilde{V}_{d}$ is potential on dielectric slot region and $\widetilde{V}_{c}$ is the potential on conductor strip reg ion. The potential at lower and upper surface of the conductor are $\widetilde{V}_{\mathrm{c}}^{1}\left(\beta_{\mathrm{n}}\right)+\widetilde{\mathrm{V}}_{\mathrm{d}}^{1}\left(\beta_{\mathrm{n}}\right)$ and $\widetilde{V}_{\mathrm{c}}^{2}\left(\beta_{\mathrm{n}}\right)+\widetilde{\mathrm{V}}_{\mathrm{d}}^{2}\left(\beta_{\mathrm{n}}\right)$ respectively.

$$
\tilde{\mathrm{V}}_{\mathrm{c}}\left(\beta_{\mathrm{n}}\right)+\widetilde{\mathrm{V}}_{\mathrm{d}}\left(\beta_{\mathrm{n}}\right)=\left[\begin{array}{c}
\widetilde{\mathrm{V}}_{\mathrm{c}}^{1}\left(\beta_{\mathrm{n}}\right)+\widetilde{\mathrm{V}}_{\mathrm{d}}^{1}\left(\beta_{\mathrm{n}}\right) \\
\tilde{\mathrm{V}}_{\mathrm{c}}^{2}\left(\beta_{\mathrm{n}}\right)+\widetilde{\mathrm{V}}_{\mathrm{d}}^{2}\left(\beta_{\mathrm{n}}\right)
\end{array}\right]
$$

The Green's function for multilayer CPW in Fourier domain is obtained by transverse transmission line (TTL) technique. The Green's function for the multilayer CPW shown in Figure 1 is given by

$$
\widetilde{\mathrm{G}}\left(\beta_{\mathrm{n}}\right)=\left[\begin{array}{ll}
\widetilde{\mathrm{G}}_{11}\left(\beta_{\mathrm{n}}\right) & \widetilde{\mathrm{G}}_{12}\left(\beta_{\mathrm{n}}\right) \\
\widetilde{\mathrm{G}}_{21}\left(\beta_{\mathrm{n}}\right) & \widetilde{\mathrm{G}}_{22}\left(\beta_{\mathrm{n}}\right)
\end{array}\right]
$$

where

$$
\begin{gathered}
\widetilde{\mathrm{G}}_{11}\left(\beta_{\mathrm{n}}\right)=\frac{1}{\beta_{\mathrm{n}}\left(\mathrm{GF}_{1}+\mathrm{GF}_{3}\right)} \\
\widetilde{\mathrm{G}}_{22}\left(\beta_{\mathrm{n}}\right)=\frac{1}{\beta_{\mathrm{n}}\left(\mathrm{GF}_{2}+\mathrm{GF}_{4}\right)} \\
\widetilde{\mathrm{G}}_{12}\left(\beta_{\mathrm{n}}\right)=\widetilde{\mathrm{G}}_{22}\left(\beta_{\mathrm{n}}\right)\left[\frac{\varepsilon_{\mathrm{r} 3} / \sinh \left(\beta_{\mathrm{n}} \mathrm{h}_{3}\right)}{\varepsilon_{\mathrm{r} 3} \operatorname{coth}\left(\beta_{\mathrm{n}} \mathrm{h}_{3}\right)+\mathrm{GF}_{1}}\right] \\
\widetilde{\mathrm{G}}_{21}\left(\beta_{\mathrm{n}}\right)=\widetilde{\mathrm{G}}_{11}\left(\beta_{\mathrm{n}}\right)\left[\frac{\varepsilon_{\mathrm{r} 3} / \sinh \left(\beta_{\mathrm{n}} \mathrm{h}_{3}\right)}{\varepsilon_{\mathrm{r} 3} \operatorname{coth}\left(\beta_{\mathrm{n}} \mathrm{h}_{3}\right)+\mathrm{GF}_{2}}\right] \\
\mathrm{GF}_{1}=\varepsilon_{\mathrm{r} 2}\left[\frac{\varepsilon_{\mathrm{r} 2}+\varepsilon_{\mathrm{r} 1} \operatorname{coth}\left(\beta_{\mathrm{n}} \mathrm{h}_{1}\right) \operatorname{coth}\left(\beta_{\mathrm{n}} \mathrm{h}_{2}\right)}{\varepsilon_{\mathrm{r} 1} \operatorname{coth}\left(\beta_{\mathrm{n}} \mathrm{h}_{1}\right)+\varepsilon_{\mathrm{r} 2} \operatorname{coth}\left(\beta_{\mathrm{n}} \mathrm{h}_{2}\right)}\right] \\
\mathrm{GF}_{2}=\varepsilon_{\mathrm{r} 4}\left[\frac{\varepsilon_{\mathrm{r} 4}+\varepsilon_{\mathrm{r} 5} \operatorname{coth}\left(\beta_{\mathrm{n}} \mathrm{h}_{4}\right) \operatorname{coth}\left(\beta_{\mathrm{n}} \mathrm{h}_{5}\right)}{\varepsilon_{\mathrm{r} 4} \operatorname{coth}\left(\beta_{\mathrm{n}} \mathrm{h}_{4}\right)+\varepsilon_{\mathrm{r} 5} \operatorname{coth}\left(\beta_{\mathrm{n}} \mathrm{h}_{5}\right)}\right] \\
\mathrm{GF}_{3}=\varepsilon_{\mathrm{r} 3}\left[\frac{\varepsilon_{\mathrm{r} 3}+\operatorname{coth}\left(\beta_{\mathrm{n}} \mathrm{h}_{3}\right) \mathrm{GF}_{2}}{\varepsilon_{\mathrm{r} 3} \operatorname{coth}\left(\beta_{\mathrm{n}} \mathrm{h}_{3}\right)+\mathrm{GF}_{2}}\right] \\
\mathrm{GF}_{4}=\varepsilon_{\mathrm{r} 3}\left[\frac{\varepsilon_{\mathrm{r} 3}+\operatorname{coth}\left(\beta_{\mathrm{n}} \mathrm{h}_{3}\right) \mathrm{GF}_{1}}{\varepsilon_{\mathrm{r} 3} \operatorname{coth}\left(\beta_{\mathrm{n}} \mathrm{h}_{3}\right)+\mathrm{GF}_{1}}\right]
\end{gathered}
$$

On substituting Eq.(1), Eq.(3) and Eq.(4) in Eq.(2), $\left[\begin{array}{cc}\widetilde{G}_{11}\left(\beta_{n}\right) & \widetilde{G}_{12}\left(\beta_{n}\right) \\ \widetilde{G}_{21}\left(\beta_{n}\right) & \widetilde{G}_{22}\left(\beta_{n}\right)\end{array}\right] \times$

$$
\begin{aligned}
& {\left[\begin{array}{l}
N_{1} a_{i}^{1} \widetilde{\rho}_{s 1 i}\left(\beta_{n}\right)+\sum_{i=1}^{N_{1}} b_{i}^{1} \widetilde{\rho}_{s 2 i}\left(\beta_{n}\right)+\sum_{i=1}^{N_{1}} c_{i}^{1} \widetilde{\rho}_{s 3 i}\left(\beta_{n}\right) \\
N_{1}^{N} a_{1}^{2} \widetilde{\rho}_{s 1 i}\left(\beta_{n}\right)+\sum_{i=1}^{N_{1}} b_{i}^{2} \widetilde{\rho}_{s 2 i}\left(\beta_{n}\right)+\sum_{i=1}^{N_{1}} c_{i}^{2} \widetilde{\rho}_{s 3 i}\left(\beta_{n}\right) \\
\sum_{i=1} a_{i}
\end{array}\right]=} \\
& {\left[\begin{array}{c}
\widetilde{V}_{c}^{1}\left(\beta_{n}\right)+\widetilde{V}_{d}^{1}\left(\beta_{n}\right) \\
\widetilde{V}_{c}^{2}\left(\beta_{n}\right)+\widetilde{V}_{d}^{2}\left(\beta_{n}\right)
\end{array}\right]}
\end{aligned}
$$

Now take the inner product of Eq. (6) with testing function $\widetilde{\rho}_{\mathrm{t} 1 \mathrm{j}}\left(\beta_{\mathrm{n}}\right), \widetilde{\rho}_{\mathrm{t} 2 \mathrm{j}}\left(\beta_{\mathrm{n}}\right), \widetilde{\rho}_{\mathrm{t} 3 \mathrm{j}}\left(\beta_{\mathrm{n}}\right)$ and applying the Parseval's identity. By Galerkin's method solve for the unknown constant of the charge basis function The line capacitance per unit length of finite conductor thickness CPW is computed by substituting the constants in Eq. (7). 


$$
\frac{\mathrm{C}}{\varepsilon_{\mathrm{o}}}=\sum_{\mathrm{i}=1}^{\mathrm{N}_{1}}\left(\mathrm{a}_{\mathrm{i}}^{1} \mathrm{Q}_{\mathrm{i}}+\mathrm{a}_{\mathrm{i}}^{2} \mathrm{Q}_{\mathrm{i}}\right)
$$

where $Q_{i}=\int_{G_{1}+S_{1}}^{G_{1}+S_{1}+W} \rho_{\text {sli }}(x) d x$

The following charge distribution basis function on central and ground conductor strip is used[14].

$$
\begin{aligned}
& \rho_{\mathrm{sli}}(\mathrm{x})=\frac{\cos \left[(\mathrm{i}-1) \pi \frac{\left(\mathrm{x}-\mathrm{S}_{1}-\mathrm{G}_{1}\right)}{\mathrm{W}}\right]}{\sqrt{1-\left[\frac{2\left(\mathrm{x}-\mathrm{S}_{1}-\mathrm{G}_{1}\right)-\mathrm{W}}{\mathrm{W}}\right]^{2}}} \\
& \left(\mathrm{G}_{1}+\mathrm{S}_{1} \leq \mathrm{x} \leq \mathrm{G}_{1}+\mathrm{S}_{1}+\mathrm{W}\right) \\
& \rho_{\mathrm{s} 2 \mathrm{i}}(\mathrm{x})=\frac{\cos \left[\left(\mathrm{i}-\frac{1}{2}\right) \pi \frac{\left(\mathrm{x}-\mathrm{G}_{1}\right)}{\mathrm{G}_{1}}\right]}{\sqrt{1-\left[\frac{\mathrm{x}}{\mathrm{G}_{1}}\right]^{2}}} \\
& \left(0 \leq \mathrm{x} \leq \mathrm{G}_{1}\right) \quad \\
& \rho_{\mathrm{s} 3 \mathrm{i}}(\mathrm{x})=\frac{\cos \left[\left(\mathrm{i}-\frac{1}{2}\right) \pi \frac{\left(\mathrm{x}-\mathrm{L}+\mathrm{G}_{2}\right)}{\mathrm{G}_{2}}\right]}{\sqrt{1-\left[\frac{\mathrm{L}-\mathrm{x}}{\mathrm{G}_{2}}\right]^{2}}} \\
& \left(\mathrm{G}_{1}+\mathrm{S}_{1}+\mathrm{W}+\mathrm{S}_{2} \leq \mathrm{x} \leq \mathrm{L}\right)
\end{aligned}
$$

The characteristic impedance $\left(\mathrm{Z}^{*}\right)$ and effective die lectric constant $\left(\varepsilon_{\text {reff }}^{*}\right)$ of CPW are computed from the line capacitance of the structure filled with dielectric $\left(C_{d}^{*}\right)$ and air $\left(\mathrm{C}_{\mathrm{a}}\right)$ from the following equations,

$$
\begin{gathered}
\mathrm{Z}^{*}=\frac{1}{\mathrm{c}_{\mathrm{o}} \sqrt{\mathrm{C}_{\mathrm{d}}^{*}\left(\varepsilon_{\mathrm{r}}^{*}\right) \mathrm{C}_{\mathrm{a}}\left(\varepsilon_{\mathrm{r}}=1\right)}} \\
\varepsilon_{\text {reff }}^{*}=\frac{\mathrm{C}_{\mathrm{d}}^{*}\left(\varepsilon_{\mathrm{r}}^{*}\right)}{\mathrm{C}_{\mathrm{a}}\left(\varepsilon_{\mathrm{r}}=1\right)}
\end{gathered}
$$

where $c_{o}$ is the velocity of light in free space.

Dielectric loss of multilayer CPW is calculated by converting multilayer $\mathrm{CPW}$ structure into equivalent single layer CPW structure using SLR method. The complex effective relative permittivity is co mputed by -

$$
\begin{gathered}
\varepsilon_{\text {reff }}^{*}=\frac{\mathrm{C}_{\mathrm{d}}^{*}\left(\varepsilon_{\mathrm{r}}^{*}\right)}{\mathrm{C}_{\mathrm{a}}\left(\varepsilon_{\mathrm{r}}=1\right)}=\varepsilon_{\text {reff }}^{\prime}-\mathrm{j} \varepsilon_{\text {reff }}^{\prime \prime} \\
\varepsilon_{\text {req }}^{\prime}-\mathrm{j} \varepsilon_{\text {req }}^{\prime \prime}=\frac{\left(\varepsilon_{\text {reff }}^{\prime}-\mathrm{j} \varepsilon_{\text {reff }}^{\prime \prime}-1\right)}{\mathrm{q}}+1 \\
\tan \delta_{\text {eq }}=\frac{\varepsilon_{\text {req }}^{\prime \prime}}{\varepsilon_{\text {req }}^{\prime}}=\frac{\varepsilon_{\text {reff }}^{\prime \prime}}{\varepsilon_{\text {reff }}^{\prime}+\mathrm{q}-1}
\end{gathered}
$$

where $\mathrm{q}$ is filling factor for coplanar waveguide. The dielectric loss[15] of the coplanar waveguide is given by,

$$
\alpha_{\mathrm{d}}=\frac{8.686 \pi}{\lambda_{0}} \frac{\varepsilon_{\text {req }}^{\prime}}{\sqrt{\varepsilon_{\text {reff }}^{\prime}}} \frac{\left(\varepsilon_{\text {reff }}^{\prime}-1\right)}{\left(\varepsilon_{\text {req }}^{\prime}-1\right)} \tan \left(\delta_{\text {eq }}\right)
$$

The conductor loss of CPW is computed by perturbation method (Pertb. M.), [16-18].

$$
\begin{aligned}
& \alpha_{\mathrm{c}}=\frac{\mathrm{R}_{\mathrm{s}}}{16 \mathrm{ZK}^{2}(\mathrm{k})\left(1-\mathrm{k}^{2}\right)} \times \\
& {\left[\begin{array}{l}
\frac{1}{\mathrm{a}} \ln \left(\left(\frac{2 \mathrm{a}}{\Delta}-1\right)\left(\frac{\mathrm{b}-\mathrm{a}+\Delta}{\mathrm{b}+\mathrm{a}+\Delta}\right)\right)+ \\
\frac{1}{\mathrm{~b}} \ln \left(\left(\frac{2 \mathrm{~b}}{\Delta}-1\right)\left(\frac{\mathrm{b}-\mathrm{a}+\Delta}{\mathrm{b}+\mathrm{a}-\Delta}\right)\right)
\end{array}\right]}
\end{aligned}
$$

where $\mathrm{K}(\mathrm{k})$ is complete elliptic integral of first kind, $\Delta$ is stopping distance, $\mathrm{k}=\mathrm{a} / \mathrm{b}, \mathrm{a}=\mathrm{W} / 2, \mathrm{~b}=\mathrm{S}_{1}+\mathrm{W} / 2$. For symmetric configuration of CPW structure $\mathrm{S}_{1}=\mathrm{S}_{2}=\mathrm{S}$.

$$
\begin{gathered}
\text { where } R_{s}=\omega \mu_{c} h_{3} \operatorname{Im}\left[\frac{\cot \left(k_{c} h_{3}\right)+\csc \left(k_{c} h_{3}\right)}{k_{c} h_{3}}\right] \\
k_{c}=\omega \sqrt{\mu_{o} \varepsilon_{o}}\left[1-j \frac{\sigma_{c}}{\omega \varepsilon_{o}}\right]^{1 / 2}
\end{gathered}
$$

For single ground coplanar waveguide the conductor loss is computed from[9],

$$
\alpha_{\mathrm{c}}=\frac{\mathrm{R}_{\mathrm{s}} \sqrt{\varepsilon_{\mathrm{reff}}}}{480 \pi \mathrm{K}\left(\mathrm{k}_{2}\right) \mathrm{K}\left(\mathrm{k}_{2}^{\prime}\right)}\left[\Phi_{1}+\Phi_{2}\right]
$$

where $\Phi_{1}=\frac{1}{2 \mathrm{a}} \log \left(\frac{2 \mathrm{ak}_{2}^{\prime}}{\Delta}\right) \Phi_{2}=\frac{1}{\mathrm{~b}-\mathrm{a}} \log \left(\frac{(\mathrm{b}-\mathrm{a}) \mathrm{k}_{2}}{\Delta}\right)$

$$
\mathrm{k}_{2}=\sqrt{\frac{2 \mathrm{a}}{\mathrm{a}+\mathrm{b}}}, \mathrm{k}_{2}^{\prime}=\sqrt{\frac{\mathrm{b}-\mathrm{a}}{\mathrm{b}+\mathrm{a}}}
$$

\section{Dispersion Analysis of Multilayer CPW}

A dispersion formula[19] for effective dielectric constant has been proposed for coplanar waveguide

$$
\varepsilon_{\text {reff }}(\mathrm{f})=\left[\sqrt{\varepsilon_{\text {reff }}(\mathrm{f}=0)}+\frac{\sqrt{\varepsilon_{\mathrm{r}}}-\sqrt{\varepsilon_{\text {reff }}(\mathrm{f}=0)}}{\left(1+\mathrm{aF}^{-\mathrm{b}}\right)}\right]^{2}
$$

where $F=\frac{f}{f_{T E}}, f_{T E}=\frac{c_{o}}{4 h \sqrt{\varepsilon_{r}-1}}$ is the cutoff frequency of the $\mathrm{TE}_{1}$ mode, $\mathrm{b}=1.8$

$$
\begin{aligned}
& \log (\mathrm{a})=\mathrm{u} \log \left(\frac{\mathrm{W}}{\mathrm{S}}\right)+\mathrm{v} \\
& \mathrm{u}=0.54-0.64 \mathrm{p}+0.015 \mathrm{p}^{2}
\end{aligned}
$$




$$
\begin{gathered}
\mathrm{v}=0.43-0.86 \mathrm{p}+0.540 \mathrm{p}^{2} \\
\mathrm{p}=\log \left(\frac{\mathrm{W}}{\mathrm{h}}\right)
\end{gathered}
$$

This dispersion formula was obtained under the assumption of infinitely thin conductors and infinity conductivity. To account the dispersion at low frequency an approximation for computation of increased inductance due to skin effect in strip conductor is used here. At the lower end of RF and microwave, the finite conductivity of a strip permits penetration of magnetic field inside the conductor, causing increase in effective relative permittivity and impedance with decrease in operating frequency. The penetration of the magnetic field in a conducting strip increases the effective permeability of the CPW. The effective permeability, expressed by a factor $\mathrm{K}$, is computed on the air-substrate CPW by the following expression in term of capacitance. At lower frequency, we have $\mathrm{K}>>1$ and at higher frequency $\mathrm{K} \rightarrow 1$. As the frequency decreases, the field penetration inside the conductor increases and effective relative permittivity increases at low frequency.

$$
\begin{gathered}
\varepsilon_{\text {reff }}(\mathrm{f})=\left[\begin{array}{l}
\sqrt{\mathrm{K} \varepsilon_{\text {reff }}(\mathrm{f}=0)}+ \\
\frac{\sqrt{\varepsilon_{\mathrm{r}}}-\sqrt{\mathrm{K} \varepsilon_{\text {reff }}(\mathrm{f}=0)}}{\left(1+\mathrm{aF} \mathrm{F}^{-\mathrm{b}}\right)}
\end{array}\right]^{2} \\
\mathrm{Z}_{\mathrm{o}}(\mathrm{f})=\frac{\mathrm{Z}_{\mathrm{o}}(\mathrm{f}=0)}{\varepsilon_{\text {reff }}(\mathrm{f}=0)} \sqrt{\mathrm{K}}
\end{gathered}
$$

where $\mathrm{K}=\frac{\mathrm{C}_{\mathrm{o}}\left(\delta_{\mathrm{s}}=0, \varepsilon_{\mathrm{r}}=1\right)}{\mathrm{C}\left(\delta_{\mathrm{s}}, \varepsilon_{\mathrm{r}}=1\right)}$

$\mathrm{C}_{\mathrm{o}}\left(\delta_{\mathrm{s}}=0, \varepsilon_{\mathrm{r}}=1\right)$ is the capacitance without skin effect and $\mathrm{C}\left(\delta_{\mathrm{s}}, \varepsilon_{\mathrm{r}}=1\right)$ is capacitance with skin effect on air substrate of CPW transmission line.

\section{Circuit Model of CPW}

The primary line constants of a multilayer coplanar waveguide are resistance $(R)$, conductance $(G)$, capacitance (C) and inductance (L). These parameters are computed from the conductor loss, dielectric loss, real part of effective relative permittivity and impedance. high dielectric constant dis appears at high frequency.

$$
\begin{gathered}
\mathrm{R}=2 \mathrm{Z}_{\mathrm{o}} \alpha_{\mathrm{c}} \\
\mathrm{G}=\frac{2 \alpha_{\mathrm{d}}}{\mathrm{Z}_{\mathrm{o}}} \\
\mathrm{C}=\frac{\sqrt{\varepsilon_{\mathrm{reff}}^{\prime}}}{\mathrm{c}_{\mathrm{o}} \mathrm{Z}_{\mathrm{o}}} \\
\mathrm{L}=\frac{\mathrm{Z}_{\mathrm{o}} \sqrt{\varepsilon_{\mathrm{reff}}^{\prime}}}{\mathrm{c}_{\mathrm{o}}}
\end{gathered}
$$

The circuit model can calculate the complex characteristic impedance, phase constant and total loss of the structure. The complex characteristic impedance $\left(\mathrm{Z}_{\mathrm{o}}^{*}\right)$ and complex propagation constant $\left(\gamma^{*}\right)$ is given by,

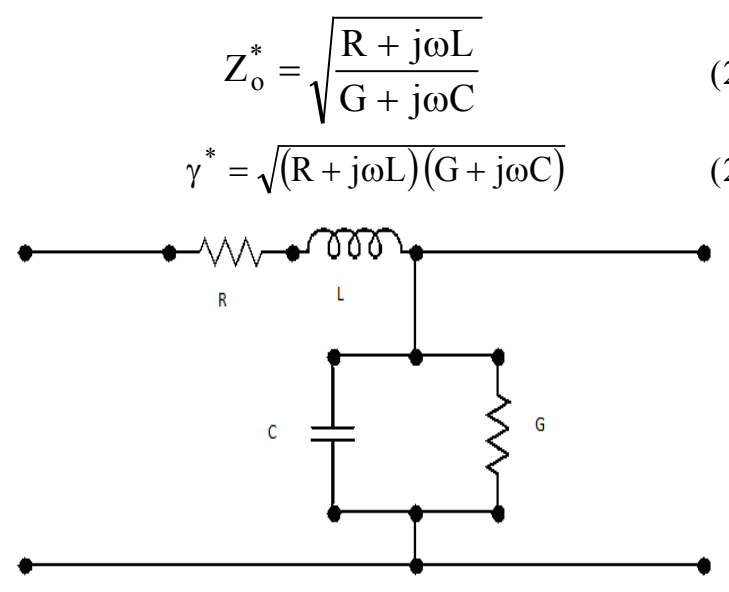

Figure 2. Circuit Model of Coplanar Waveguide

The total loss is $\alpha \mathrm{T}=\operatorname{Re}\left(\gamma^{*}\right)$ Np per unit length, the phase constant is $\beta=\operatorname{Im}\left(\gamma^{*}\right)$ radian per unit length. The effective dielectric constant is calculated from the following relation, $\varepsilon_{\mathrm{r} \text { eff }}=\left(\beta / \beta_{\mathrm{o}}\right)^{2}$, where $\beta \mathrm{o}$ is free-space phase constant.

\section{Result and Discussion}

In this section, first we have validated the static SDA formulation that include two layer conductor thickness model against EM simulator- Ansoft High Frequency Structure Simulator (HFSS)[20] and Computer Simulation Technology (CST) microwave studio[21].

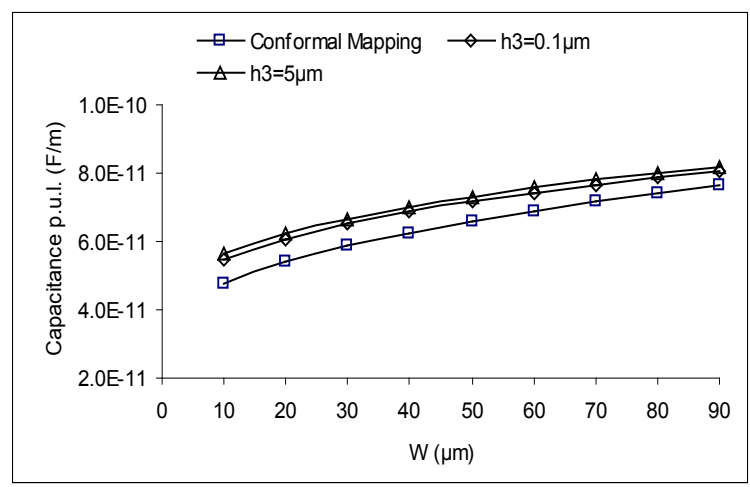

(a)

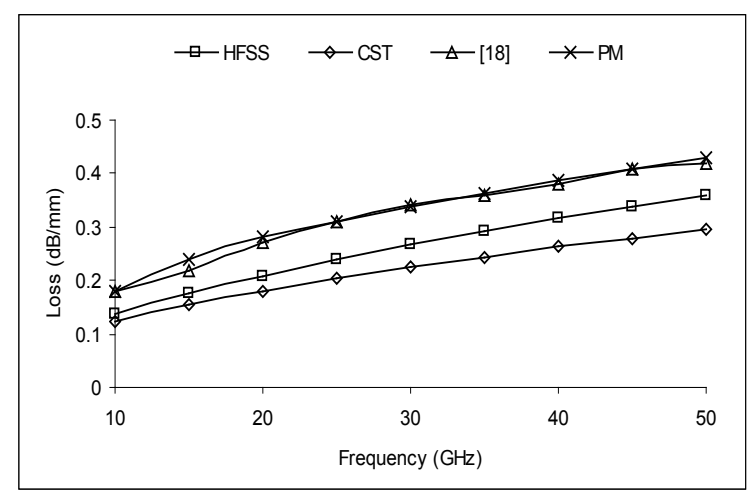

(b) 


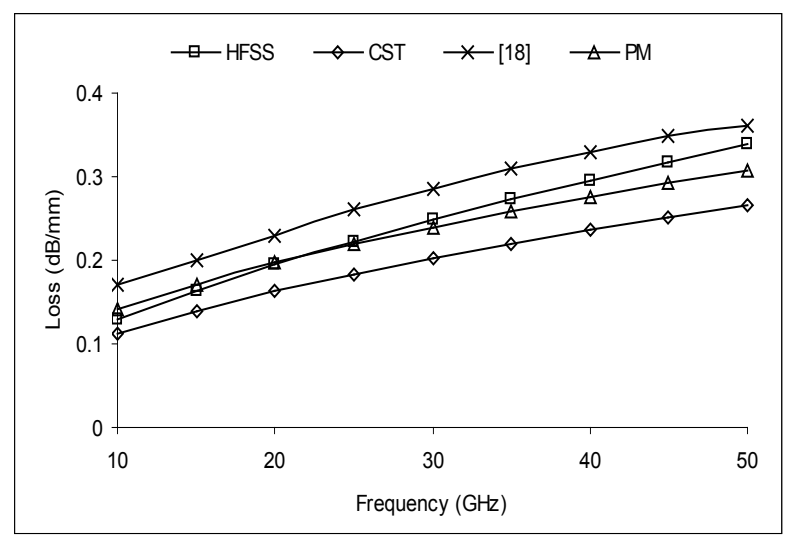

(c)

Figure 3. (a) Variation of Capacitance p.u.l. of CPW with the width of central conduct or $\mathrm{S}_{1}=50 \mu \mathrm{m}, \mathrm{S}_{2}=50 \mu \mathrm{m}, \mathrm{h}_{1}=500 \mu \mathrm{m}, \mathrm{h}_{2}=5 \mu \mathrm{m}, \mathrm{h}_{4} \rightarrow \infty, \varepsilon_{\mathrm{r} 1}=3.78$, $\varepsilon_{\mathrm{r} 2}=12.9, \varepsilon_{\mathrm{r} 4}=1.0$. Loss versus frequency of coplanar waveguide $(\mathrm{b}) \mathrm{h}_{3}=1.5$ $\mu \mathrm{m}$, (c) $\mathrm{h}_{3}=3.0 \mu \mathrm{m}, \mathrm{h}_{1} \rightarrow \infty, \mathrm{h}_{2}=600 \mu \mathrm{m}, \mathrm{h}_{4}=0, \mathrm{~h}_{5} \rightarrow \infty, \varepsilon_{\mathrm{r} 1}=1, \varepsilon_{\mathrm{r} 2}=12.9, \varepsilon_{15}=1$, $\tan \delta_{2}=0.0003, \mathrm{~W}=10 \mu \mathrm{m}, \mathrm{S}_{1}=20 \mu \mathrm{m}, \sigma=3.0 \times 10^{7} \mathrm{~S} / \mathrm{m}$

Next we validated the frequency dependent, i.e., dynamic line parameters at low frequency obtained from the present model (PM) against the result from HFSS and CST. In Figure 3(a) the capacitance per unit length (p.u.1.) of CPW is compared with conformal mapping method. In Figure 3(b)-(c) the loss of CPW are compared against the HFSS, CST present model (PM) and[18] for different conductor thickness. Figure 4(a) show the effects of conductor thickness on effective die lectric constant and impedance for multilayer CPW. The effective dielectric constant and impedance decreases with increase of conductor thickness. In our study HFSS is taken as reference. The simulation is carried at $1 \mathrm{Gh} z$ to compute $\varepsilon_{\mathrm{eff}}(\mathrm{f}=0), \mathrm{Z}(\mathrm{f}=0)$ and dielectric loss. For these computations, the strip conductor is treated as a perfect conductor. The finite conductivity is considered for computation of frequency dependent line parameters. The variation in line parameters are shown with respect to conductor thickness between $3 \mu \mathrm{m}-30 \mu \mathrm{m}$. The average deviation in effective dielectric constant of present model and CST with HFSS are $2.21 \%$ and $0.47 \%$ respectively.

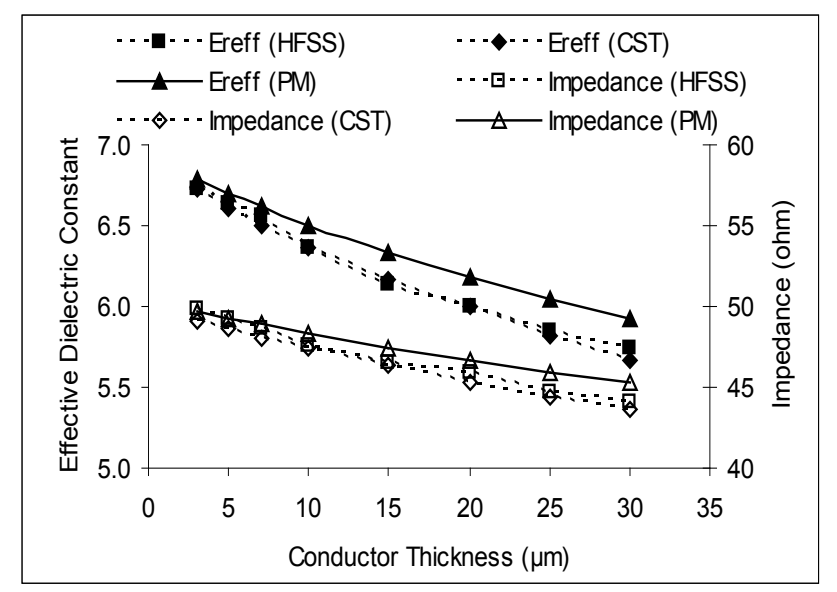

(a)

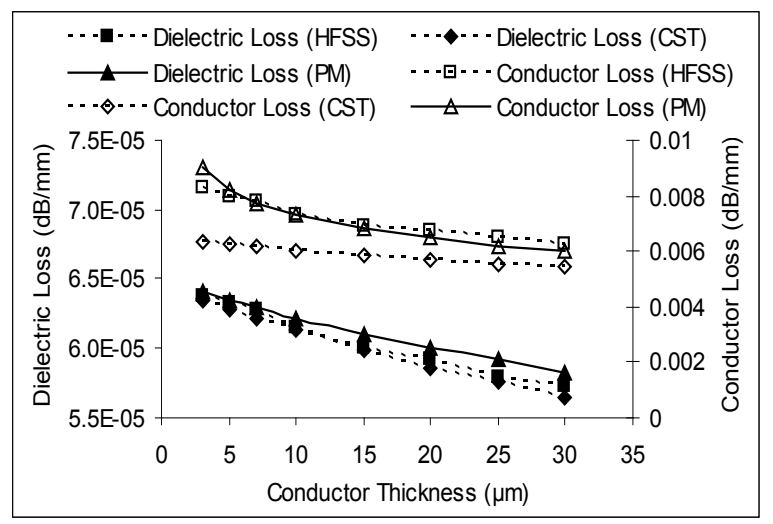

(b)

Figure 4. Variation of (a) Effective dielectric constant and impedance (b) dielectric and conductor loss with conductor thickness of CPW $\mathrm{h}_{1}=254 \mu \mathrm{m}$, (b) $\mathrm{h}_{2}=254 \mu \mathrm{m}, \mathrm{h}_{4}=0 \mu \mathrm{m}, \mathrm{h}_{5}=10 \mathrm{H}, \varepsilon_{\mathrm{rl}}=9.8, \varepsilon_{\mathrm{r} 2}=12.9, \varepsilon_{\mathrm{r} 5}=1, \tan \delta_{1}=0.0001$, $\tan \delta_{2}=0.0003, \mathrm{~W}=120 \mu \mathrm{m}, \mathrm{S}_{1}=90 \mu \mathrm{m}, \sigma=4.1 \times 10^{7} \mathrm{~S} / \mathrm{m}, \mathrm{H}=\mathrm{h}_{1}+\mathrm{h}_{2}$

The average deviation in impedance of present model and CST with HFSS are $1.35 \%$ and $0.96 \%$ respectively. Figure (4b) shows the effects of conductor thickness on dielectric loss and conductor loss. The average deviations in conductor loss of present model and CST with HFSS are $3.35 \%$ and $17.77 \%$ respectively. The average deviations in dielectric loss of present model and CST with HFSS are $1.17 \%$ and $0.67 \%$ respectively. Figure 5(a)-(e) shows variation of effective dielectric constant, impedance, dielectric loss and conductor loss for multilayer CPW with frequency.

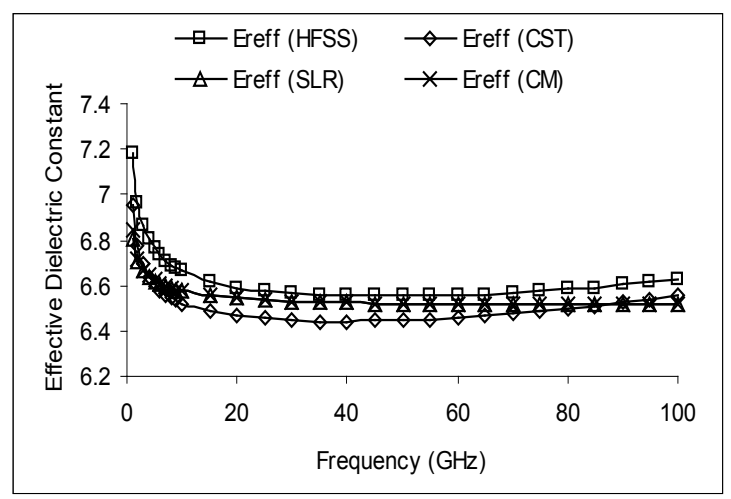

(a)

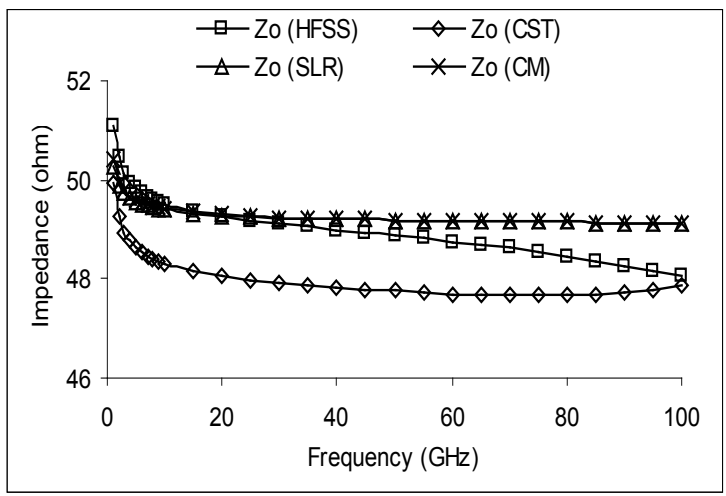

(b) 


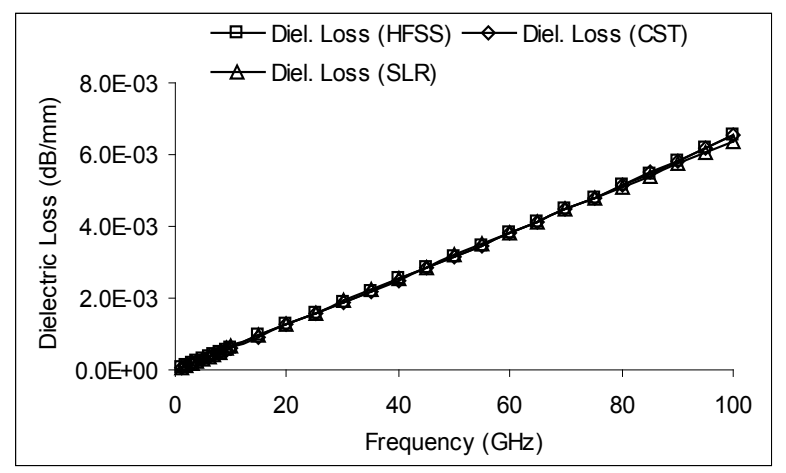

(c)

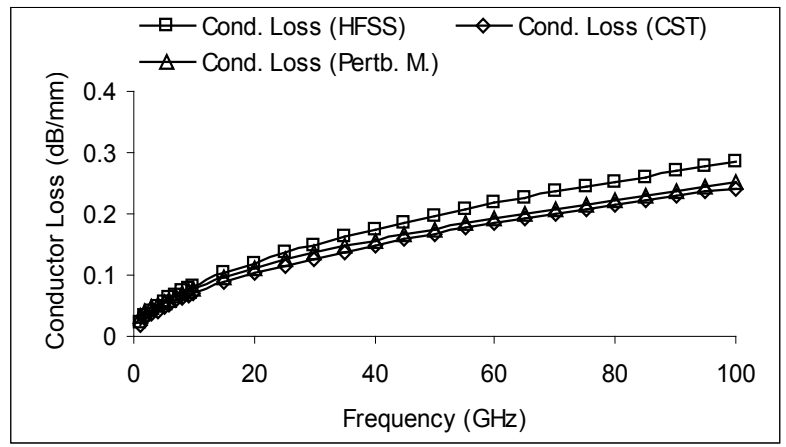

(d)

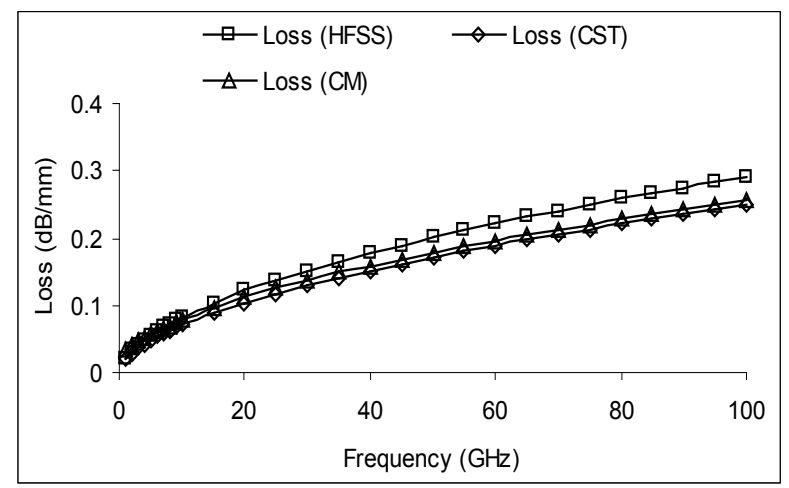

(e)

Figure 5. Propagation characteristics of coplanar waveguide (a) effective dielectric constant (b) impedance (c) dielectric loss (d) conductor loss (e) Total Loss, $\mathrm{h}_{1}=127 \mu \mathrm{m}, \mathrm{h}_{2}=254 \mu \mathrm{m}, \mathrm{h}_{3}=3 \mu \mathrm{m}, \mathrm{h}_{4}=0, \mathrm{~h}_{5}=10 \mathrm{H}, \varepsilon_{\mathrm{rl}}=9.8$, $\varepsilon_{\mathrm{r} 2}=12.9, \varepsilon_{15}=1, \tan \delta_{1}=0.0001, \tan \delta_{2}=0.0003, \mathrm{~W}=24 \mu \mathrm{m}, \mathrm{S}_{1}=18 \mu \mathrm{m}, \sigma=$ $4.1 \times 10^{7} \mathrm{~S} / \mathrm{m}$

The results are further improved on using the circuit model (CM). In Figure 6(a)-(b) the dielectric loss and conductor loss of multilayer CPW are compared for 1-100 $\mathrm{GHz}$.

The SLR method has been used to compute the frequency dependent effective dielectric constant, impedance, dielectric loss and conductor loss. Figure 7(a)-(c) show the variation of attenuation constant of multilayer CPW for different conductor thickness by circuit model. Figure 8(a)-(b) show the variation of effective dielectric constant and loss of multilayer micro coplanar strip (MCS) with frequency.
The shielded multilayer CPW structure shown in Figure 1 can be converted into other structures such as dielectric covered CPW, suspended CPW, elevated CPW, top shield without conductor back etc. The dispersion in effective dielectric constant of CPW at low frequency due to finite conductivity of strip conductor is also incorporated. As the frequency decreases, the effective relative permittivity increases due to skin effect in conductor. The impedance of CPW line also shows the similar behaviour at low frequency region. It is clearly seen that good agreement exists between present model and EM simu lator.

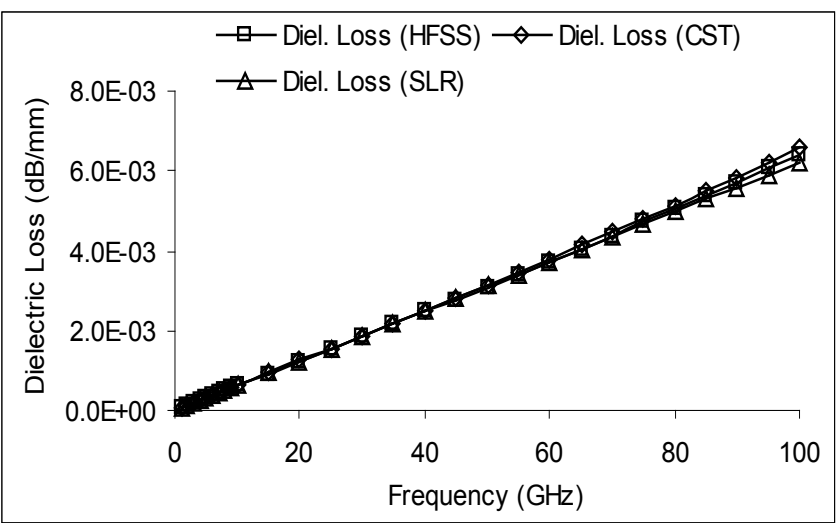

(a)

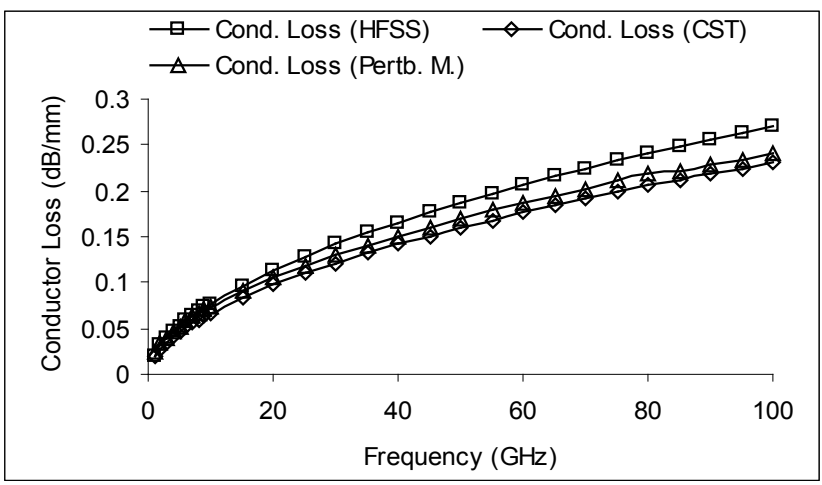

(b)

Figure 6. Losses of coplanar waveguide (a) dielectric loss (b) conductor loss, $\mathrm{h}_{1}=127 \mu \mathrm{m}, \mathrm{h}_{2}=254 \mu \mathrm{m}, \mathrm{h}_{3}=5 \mu \mathrm{m}, \mathrm{h}_{4}=0, \mathrm{~h}_{5}=10 \mathrm{H}, \varepsilon_{\mathrm{rl}}=9.8, \varepsilon_{2}=12.9$, $\varepsilon_{\mathrm{r} 5}=1, \tan \delta_{1}=0.0001, \tan \delta_{2}=0.0003, \mathrm{~W}=24 \mu \mathrm{m}, \mathrm{S}_{1}=18 \mu \mathrm{m}, \sigma=4.1 \times 10^{7} \mathrm{~S} / \mathrm{m}$

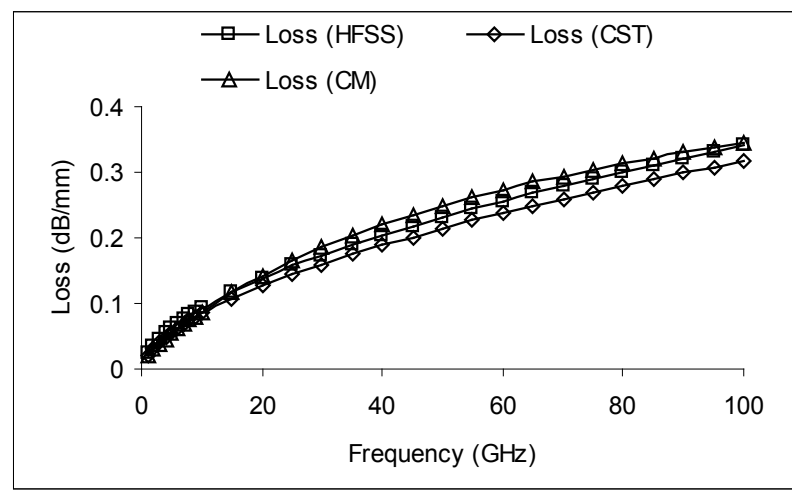

(a) 


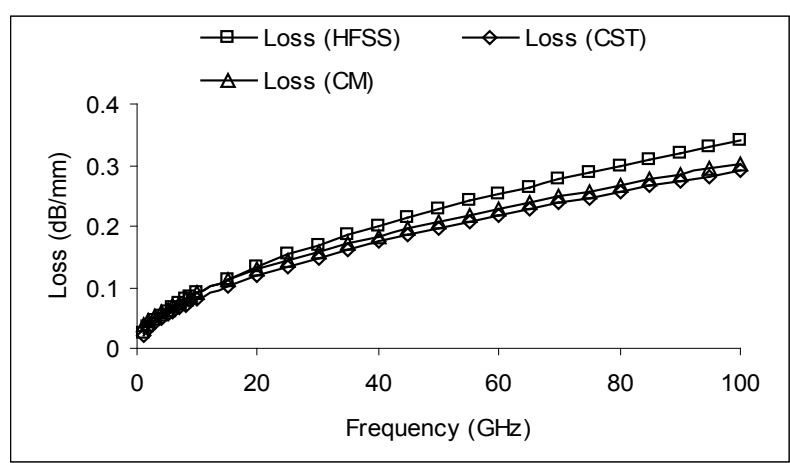

(b)

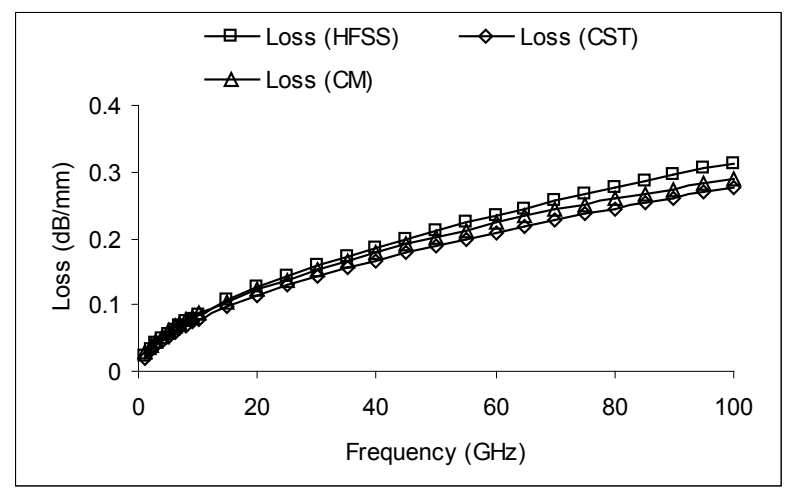

(c)

Figure 7. Attenuation constant of coplanar waveguide with frequency from circuit model (a) $h_{3}=1 \mu \mathrm{m}$ (b) $h_{3}=3 \mu \mathrm{m}$ (c) $h_{3}=5 \mu \mathrm{m}$, $\mathrm{h}_{1}=127 \mu \mathrm{m}, \mathrm{h}_{2}=254 \mu \mathrm{m}, \mathrm{h}_{4}=0, \mathrm{~h}_{5}=10 \mathrm{H}, \varepsilon_{\mathrm{rl}}=3.78, \varepsilon_{\mathrm{r} 2}=9.6, \varepsilon_{\mathfrak{5}}=1$, $\tan \delta_{1}=0.0001, \tan \delta_{2}=0.0003, \mathrm{~W}=24 \mu \mathrm{m}, \mathrm{S}_{1}=18 \mu \mathrm{m}$

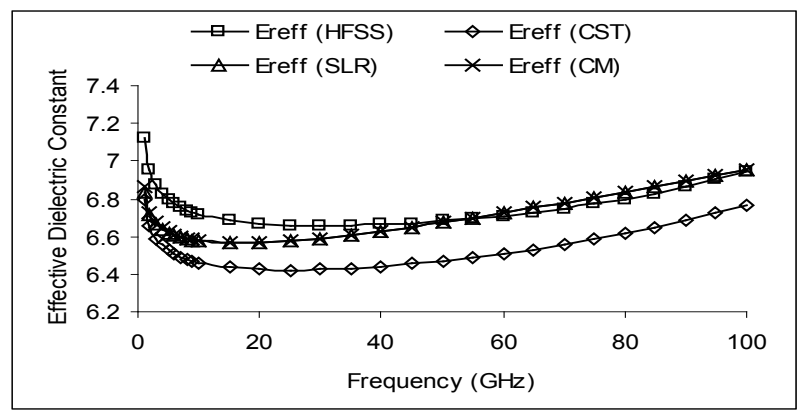

(a)

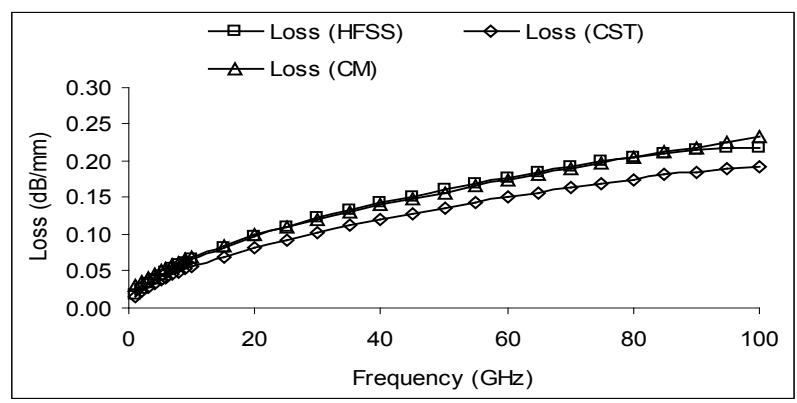

(b)

Figure 8. Multilayer micro coplanar strip (MCS) (a) effective dielectric constant (b) loss, $\mathrm{h}_{1}=127 \mu \mathrm{m}, \mathrm{h}_{2}=254 \mu \mathrm{m}, \mathrm{h}_{3}=3 \mu \mathrm{m}, \mathrm{h}_{4}=0, \mathrm{~h}_{5}=10 \mathrm{H}, \varepsilon_{\mathrm{H}}=9.8$, $\varepsilon_{\mathrm{r} 2}=12.9, \varepsilon_{\mathrm{D}}=1, \tan \delta_{1}=0.0001, \tan \delta_{2}=0.0003, \mathrm{~W}=24 \mu \mathrm{m}, \mathrm{S}_{1}=18 \mu \mathrm{m}, \sigma=$ $4.1 \times 10^{7} \mathrm{~S} / \mathrm{m}$

\section{Conclusions}

In this paper, computationally efficient quasi-static SDA is used to study the effect of conductor thickness on effective dielectric constant, impedance, dielectric loss and conductor loss of shielded multilayer CPW on is otropic layered media. The accuracy of the method is investigated through the comparis on between results obtained using quasi-static SDA, Ansoft HFSS, CST software and the agreement is very good. The SDA formulation incorporates the two layer model of conductor thickness and concept of permeability due to field penetration in the imperfect conductor. This formulation accounts for the effect of conductor thickness and low frequency dispersion on computation of quasi-static effective relative permittivity and characteristic impedance. The models accuracy is comparable to the accuracy of HFSS and CST, without using complex and time consuming full wave methods. The present formulation can be incorporated in the CAD of CPW based circuits and other planar transmission line with finite conductor thickness conveniently.

\section{REFERENCES}

[1] T. Kitazawa and Y. Hayashi, "Quasistatic and Hybrid Mode Analysis of Shielded Coplanar Waveguide with metal coating," IEE Proceedings, vol.134, no.3, pp.321-323, June 1987.

[2] T. Kitazawa and T. Itoh, "Propagation Characteristics of Coplanar-Type Transmission Lines with Lossy Media," IEEE Transactions on Microwave Theory and Techniques, vol.39, no.10, pp.1694-1700, October 1991.

[3] Eikichi Yamashita and Kazuhiko Atsuki, "Analysis of Thick-Strip Transmission Lines," IEEE Transactions on Microwave Theory and Techniques, vol.19, pp.120-122, January 1971.

[4] V. K. Tripathi and R. T. Kollipara, "Quasi-TEM Spectral Domain Analysis of Thick Microstrip for Microwave and Digital Integrated Circuits," Electronics Letters, vol.25, no. 18, pp.1253-1254, August 1989.

[5] Jeng-Yi Ke and Chun Hsiung Chun, "Dispersion and Attenuation Characteristics of Coplanar Waveguides with Finite Metallization Thickness and Conductivity," IEEE Transactions on Microwave Theory and Techniques, vol.43, no.5, pp.1128-1135, May 1995.

[6] Ian McGgregor, Fatemeh Aghamoradi, and Khaled Elgaid, "An Approximate Analytical Model for the Quasi-Static Parameters of Elevated CPW Lines," IEEE Transactions on Microwave Theory and Techniques, vol.58, no.12, pp.3809-3814, December 2010.

[7] Frank Schneider, Thorsten Tischler, Wolfang Heinrich, "Modeling Dispersion and Radiation Characteristics of Conductor-Backed CPW With Finite Ground Width," IEEE Transactions on Microwave Theory and Techniques, vol.51, no.1, pp.137-143, January 2003. 
[8] S. Gevorgian, T. Martinsson, A. Deleniv, E. Kollberg, and I. Vendik, "Simple and accurate dispersion expression for the effective dielectric constant of coplanar waveguides," IEE Proceedings Microwave Antennas Propagation, vol. 44, no. 2, pp. 145-148, April 1997.

[9] Giovanni Ghione, “A CAD-Oriented Analytical Model for the Losses of General Asymmetric Coplanar Lines in Hybrid and Monolithic MICs," IEEE Transactions on Microwave Theory and Techniques, vol.41, no.9, pp.1499-1510, September 1993.

[10] Kee Woon TAN and Sener Uysal, "Analysis and Design of Conductor-Backed Asymmetric Coplanar Waveguide Lines Using Conformal Mapping Techniques and Their Application to End-Coupled Filters," IEICE Transactions Electron, vol. E82-C, no. 7, pp.1098-1103, July 1999.

[11] Spartak Gevorgian, L. J. Peter Linner, and Erik L. Kolberg, "CAD Models for Shielded Multilayered CPW," IEEE Transactions on Microwave Theory and Techniques, vol.43, no.4, pp.772-779, April 1995.

[12] E. Yamashita, Ke Ren Li, Yoichi Suzuki, "Characterization Method and Simple Design Formulas of MCS Lines Proposed for MMIC's," IEEE Transactions on Microwave Theory and Techniques, vol.35, no.12, pp.1355-1362, December 1987.

[13] Y. B. Park, G. H. Park, H. H. Park, K. Y. Jung, "Capacitance of Cop lanar Waveguid es in multilay er Dielectric Substrates ," Microwave and Optical Technology Letters, vol.54, pp. 1886-1889, August 2012.
[14] Cam Nguyen, Analysis Methods for RF, Microwave, and Millimeter-Wave Planar Transmission Line Structures, John Wiley \& Sons, Inc., 2000.

[15] A. K. Verma, Nasimuddin, and E. K. Sharma, "Analy sis and circuit model of a multilayer semiconductor slow-wave microstrip line," IEE Proc. Microwave Antennas Propag., vol. 155, no. 5, pp. 441-449, October 2004.

[16] R. N. Simon, Coplanar Waveguide Circuits, Components and Systems, Wiley-Interscience, 2001.

[17] C. L. Holloway, E. F. Kuester, “A Quasi-Closed Form Expression for the Conductor Loss of CPW lines with an Investigation of Edge Shape Effects," IEEE Transactions on Microwave Theory and Techniques, vol.43, no.12, pp.2695-2701, December 1995.

[18] Mehmet Duyar, Volkan Akan, Erdem Yazgan, and Mehmet Bayrak, "Analytical Attenuation Calculation of Asymmetrical Coplanar Waveguide with Finite Extent Ground Planes for Coplanar Waveguide Mode," Microwave and Optical Technology Letters, vol.49, pp.2082-2087, December 2007.

[19] G. Hasnain, A. Dienes, and J. R. Whinnery, "Dispersion of Picosecond Pulses in Coplanar Transmission Lines," IEEE Transactions on Microwave Theory and Techniques, vol.34, no.6, pp.738-741, June 1986.

[20] Ansoft HFSS.

[21] CST Microwave Studio. 